\title{
PARADIGMAS DE ADMINISTRAÇÃO E LEGITIMIDADE: A DEMOCRACIA COMO FORMA DE DOMINAÇÃO
}

\author{
Paradigms of governance and legitimacy: democracy as a form of domination
}

\author{
Elcio Gustavo Benini* \\ Édi Augusto Benini** \\ Gabriel Gualhanone Nemirovsky**
}

\section{RESUMO}

Este texto teve como objetivo a construção de um esquema teórico analítico e representativo das práticas e ações sociais formadoras de paradigmas históricos de administração. Especificamente, analisou a relação entre a ação social e a sua construção legitimadora, de dominação e aceitação, tendo em pauta os seus princípios estruturantes e instituições concretas, assim como as dimensões moral e material que podem condicionar a ação e a sua construção cognitiva de significação. Como procedimento de pesquisa e análise, partiu-se da vinculação entre as categorias lógicas e suas determinações históricas, pari passu com a exposição das contradições das abordagens que elevaram tais categorias ao plano de um desenvolvimento ontológico racional sem acúmulos e historicidade. Concluiu-se que, ao se considerar a destrutividade intransponível do sistema metabólico do capital, as formas de alteridade de administração, definidoras do paradigma de gestão societal, que poderiam ser compreendidas somente pela estruturação moral, engendram-se também como necessidade histórica, o que faz da construção do interesse público uma necessidade moral e material, indispensável para a efetivação do interesse individual emancipado ou legítimo.

Palavras-chave: Gestão societal; Democracia; Legitimação; Emancipação.

\section{ABSTRACT}

The paper aimed to build an analytical and representative theoretical framework of practices and social actions that constitue the management historical paradigms. Specifically, it analyzed the relation between social action and its legitimating construction, of domination and acceptance, regarding its structuring principles and concrete institutions, as well as the moral and material dimensions that can determine the action and its cognitive construction of meaning. As a research and analysis procedure, it started from the relation between the logical categories and their historical determinations pari passu with the exposure of the contradictions of the approaches that elevate these categories to a level of a rational ontological development without accumulations and historicity. In conclusion, when considering the insurmountable destructiveness of the capital metabolic system, the forms of management alterity, that define the societal management paradigm, which could be understood only by the moral structure, are also engendered as a historical necessity, which makes the construction of the public interest a moral and material necessity, indispensable for the realization of the emancipated or legitimate individual interest.

Keywords: Societal management; Democracy; Legitimation; Emancipation.

\footnotetext{
* Professor dos Programas de pós-graduação em Administração (PPGAD) e Administração Pública (Rede Profiap), Universidade Federal de Mato Grosso do Sul. Doutor em Educação pela Universidade Federal de Mato Grosso do Sul. E-mail: elciobenini@yahoo.com.br. ORCID: 0000-0002-0949-3062

** Professor Adjunto da Universidade Federal do Tocantins e Coordenador do Núcleo de Economia Solidária (NESol/UFT). Doutor em Educação pela Universidade Federal de Mato Grosso do Sul e Mestre em Administração Pública e Governo pela Escola de Administração de Empresas de São Paulo - Fundação Getúlio Vargas (EAESP/ FGV). E-mail: edibenini@gmail.com. ORCID: 0000-0001-7285-7423

*** Professor da Universidade Federal de Mato Grosso do Sul e Pesquisador do grupo de Estudo e Pesquisa em Organizações, Trabalho e Educação (GEPOTE/CNPq). Doutorando do Programa de Pós-Graduação em Educação pela FFC/UNESP. E-mail: gabrielgnemi@gmail.com. ORCID: 0000-0002-6011-2990
} 


\section{INTRODUÇÃO}

mbora este texto possa ser interpretado como um ensaio teórico, principalmente pelo seu desfecho prescritivo-normativo, a descrição, a dedução e a indução histórica, empreendidas por meio da historicização do concreto e da abstração lógica, asseguram o rigor metodológico de pesquisa científica.

Trata-se, sem dúvida, de um texto sintetizador de experiências concretas, mas ousado pelo caminho metodológico, uma vez que dialoga com duas perspectivas, ao menos a priori, irreconciliáveis: o individualismo metodológico e o materialismo histórico.

Ao tencionar o caminho que eleva o significado atribuído pelo sujeito como uma dimensão pré-estruturante de sua conduta e, assim, da ação social - conforme explicita em pormenores o sistematizador da abordagem, Max Weber -, o texto realiza também uma análise crítica ao procedimento correlato da abordagem econômica da Escolha Pública, de James Buchanan e Gordon Tullock (1962), esta como forma de desenvolvimento ontológico daquele campo epistemológico, cuja genealogia estaria em autores como Menger (1983), Mises (1946) e Hayek (1990). Portanto, ao integrar este último campo à ideologia e à prática (neo)liberais, este trabalho expõe uma crítica ao seu desenvolvimento de negação do interesse público e ao pressuposto ontológico do ser social egoísta, focalizado em uma ação preponderantemente utilitarista e/ou instrumental, logo, resultando em formas de administração centradas nessa maneira singular de dominação.

Concomitante à crítica daquela forma particular de que o individualismo metodológico se revestiu, utilizam-se as práticas sociais concretas resultantes do movimento real entre capital, trabalho e Estado - tríade do sistema sociometabólico do capital em Mészáros (2002) - como dimensões materiais estruturantes de práticas alternativas de administração e organização produtiva e societal. Portanto, o que poderia ser visto, vulgarmente, como uma determinação moral, ganha relevo como práxis imediata de sobrevivência e reprodução, salvaguardadas as contradições representadas pela funcionalidade do imediatismo organizacional.

É nessa totalidade que se aponta o interesse público como condição sine qua non de manutenção de uma dada sociabilidade e efetivação do interesse individual. A questão é: se o significado é determinante da ação social, portanto a necessidade histórica de reprodução do metabolismo social evidencia-se como uma estrutura significante que coloca a primazia da construção do interesse público frente aos interesses individuais autônomos e isolados. É fato que essa hipótese provisória parte da constatação de que o "mercado", compreendido pela astúcia (neo)liberal como mecanismo autorregulador do bem-estar, seja posto como fantasia metafísica - principalmente quando são levadas em conta as condições materiais e as desvantagens estruturais acumuladas no processo histórico (GRAY, 1999; MÉSZÁROS, 2002; PIKETTY, 2014).

Em face do exposto, este trabalho tem como objetivo a construção de um esquema teórico representativo das práticas e ações sociais formadoras de paradigmas históricos de administração. Especificamente, analisa-se o vínculo entre a ação social e a sua construção ideológica de legitimidade ou de aceitação societária, considerando seus princípios 
edificantes e instituições concretas, assim como as dimensões moral e material que podem condicionar a ação e a sua construção cognitiva de significação.

Oportunamente, informa-se ao leitor sobre algumas contribuições epistemológicas que tangenciam as reflexões aqui desenvolvidas. No campo dos estudos organizacionais as reflexões de abrangência epistemológica, gnosiológica e ontológica apresentam a sua ontogênese nos trabalhos de Burrel e Morgan (1979), cujo modelo explicativo sobre as matrizes epistemológicas e paradigmas no campo das organizações - créditos que também devem ser atribuídos aos trabalhos de Thomas Kuhn (1969) quanto à (des)continuidade e à incomensurabilidade dos paradigmas científicos - constituíram o ponto de partida para estudos relativos aos fundamentos e visões de mundo que têm engendrado os quadros explicativos e compreensivos da realidade.

Na produção mais recente (DONALDSON, 1985; HASSARD, 1991, 1993; PARKER; MCHUGH, 1991; JACKSON; CARTER, 1993; WEAVER; GIOIA, 1994; DEETZ, 1996), observa-se o forte impacto produzido no campo dos estudos organizacionais pelo trabalho seminal de Burrel e Morgan (1979). Tal impacto pode ainda ver visualizado na coletânea de estudos de caráter epistêmico efetuada por Clegg, Hardy e Nord (1996), intitulada Handbook of Organizational Studies, cuja ampliação e divulgação das análises epistemológicas parece ter acrescentado novos elementos, expandindo assim a agenda de pesquisa. Nos trabalhos de Silveira (2013), Caldas (2005) e Paula (2016) constata-se que o debate sobre os paradigmas científicos e organizacionais continua em pleno desenvolvimento, produzindo verdadeiras "guerras de paradigmas", situação já anunciada por Jackson e Carter (1993).

Feitos esses esclarecimentos, é preciso ainda situar o leitor sobre as particularidades do caminho metodológico trilhado. Assim, não obstante em um primeiro momento o desenvolvimento lógico-formal e as categorias de sustentação aqui lançadas indiquem uma visão estrutural-fenomenológica a respeito do objeto estudado, tal ponderação deve ser interpretada apenas parcialmente, pois é na múltipla determinação entre sujeito e objeto que se busca contribuir com o desenvolvimento desse campo de estudos. Portanto, na concepção aqui exteriorizada, os paradigmas de administração não se constituem, isoladamente, em meras estruturas de informação da realidade, mas, pelo contrário, se condensam em sínteses históricas de acúmulos materiais e culturais, prático-teóricos, que se articulam no sociometabolismo como referenciais para a normatização de determinadas práticas sociais. Disto decorrem duas determinações epistêmicas.

Em primeiro lugar, funda-se a necessidade de se reestruturar a própria caracterização lógica do conceito de paradigma, deslocando-a de uma acepção positivista, como quadro interpretativo - definição que sugere sua corporificação em um construto supra-histórico e unilateralizado -, em direção à adoção de um conceito de paradigma que apresente a real dinâmica multideterminada e histórica de seu conteúdo. É nesta perspectiva que se intenta realizar uma recomposição do quadro teórico sobre as formas de dominação e legitimação, para além da sua representação limitadora já consagrada no campo dos estudos organizacionais.

Em segundo lugar, o fato dos paradigmas de administração serem tomados como existências materiais sob a forma de referenciais para a realização de práticas sociais supõe a intervenção contínua de um complexo social que se imponha como função de orientação ao ser social, permitindo que este atribua valor material/moral a determinadas posições 
teleológicas por ele pretendidas, influenciando necessariamente a adequação de meios e fins de sua atividade concreta. Sob esse estatuto, é exatamente a ideologia, ou, mais precisamente, as ideologias, que exercem a contínua intervenção sociometabólica exigida para a mediação do intercâmbio legitimação/dominação dos paradigmas de administração, o qual é essencial para a positivação e reprodução das práticas sociais adequadas às finalidades normatizadas por um dado paradigma.

Naturalmente a extensão do conhecimento científico sistematizado sobre ideologia inviabiliza a discussão, pormenorizada, que o debate sobre suas diferentes concepções merece. Em atenção a essa restrição, pontua-se brevemente neste ensaio o distanciamento diametral em relação às posições gnosiológicas e estrutural-mecanicistas que, entre outras tantas repercussões, privilegiam, consciente ou inconscientemente, notadamente a acepção de ideologia como falsa consciência, ou ainda, intentam promover o expediente arbitrário de cisão entre ciência e ideologia ${ }^{1}$. Ao contrário disso, adota-se aqui a compreensão abrangente de que o complexo da ideologia se funda ontologicamente na e pela práxis do ser social, cuja gênese constitui-se pela necessidade de mediação das relações sociais. Tal compreensão, que se aproxima da concepção lukacsiana da ideologia (LUKÁCS, 2012; 2013), é apresentada em seus pontos e contrapontos essenciais no trabalho de Vaisman (2010), segundo a qual a ideologia opera como instrumento de conscientização. Assim, em sua operação, a ideologia orientaria o exercício de determinadas práticas sociais que, uma vez cristalizadas sob uma dada normatividade, condensam-se em paradigmas particulares.

Diante dessas determinações as análises e discussões amparam-se pela conexão entre as categorias lógicas e suas determinações históricas, procedimento executado pari passu com a exposição das contradições das abordagens que elevam tais categorias ao plano de um desenvolvimento ontológico racional sem acúmulo e historicidade.

Por sua vez, por efeito teórico-metodológico, a exposição lógico-argumentativa inicia-se com a apreciação da categoria de individualismo metodológico em Weber e sua aproximação epistemológica como liberalismo econômico. Na sequência, identifica-se a análise das formas paradigmáticas de administração, por meio das categorias analíticas de legitimidade e legitimação ideológica, utilizando como objetos de análises determinadas estruturas de orientação social, como os princípios de referências, formas de controle e regulação e instituições correspondentes. A partir das pistas em nível lógico lançadas por Weber e pelas experiências históricas, demonstra-se um esquema teórico que sistematiza as formas clássicas de legitimação - tradicional, carismática e burocrática - acrescentando a forma contemporânea mais sofisticada de burocracia, que é a administração gerencial.

Encaminhada a discussão sobre as necessidades objetivas e morais no tocante à constituição do interesse público e à manutenção do metabolismo social, discussão esta pautada nas contribuições do filósofo contemporâneo István Mészáros, apresenta-se o que poderia ser reconhecido como uma quarta forma de legitimidade e/ou autoridade e seu

1. Nesse contexto, no campo dos estudos organizacionais, é oportuno realçar a posição de Tragtenberg (2012), para o qual a teoria geral da administração é ideológica na medida em que se vincula às determinações sociais reais, enquanto técnica e mediação do trabalho e, simultaneamente, enquanto sistema de deformação do real, apresentando-se como neutro e harmonizador dos conflitos. Já Motta (2003) e Bernardo (1977) corroboram com a perspectiva segundo a qual tudo é ideológica na medida em que reflete a prática de um grupo social, sendo a teoria das organizações a ideologia dos dirigentes e não dos participantes da organização. 
respectivo paradigma de administração: a legitimidade da democracia e o paradigma da gestão societal ${ }^{2}$.

\section{O INDIVIDUALISMO METODOLÓGICO EM QUESTÃO: EGOÍSMO, VALOR E INTERESSE PÚBLICO}

Uma questão recorrente e fundante de uma determinada posição epistemológica, intrínseca às Ciências Sociais, é a relação de causalidade e determinação entre sujeito e objeto. Dessa determinação deriva o entendimento das relações entre indivíduo e organizações, indivíduo e sociedade e, mutatis mutandis, entre sociedade e Estado.

Em face da importância daquela relação de determinação, faz-se mister situar o leitor sobre dois pontos: o desenvolvimento ontológico do individualismo metodológico, como um dos resultados da equação indivíduo/sociedade, e a crítica à racionalidade instrumental e moral. Esse é ponto central, pois é a partir dessa crítica, e pela aproximação epistemológica com o materialismo histórico, que se desenvolve o referencial teórico-metodológico deste estudo, percebido a partir do estruturalismo dialético ${ }^{3}$. Tal raciocínio é decisivo para a reflexão aqui articulada, pois enfatiza a não negligência das estruturas significantes que condicionam e/ou pré-determinam a ação do indivíduo, sejam elas objetivas ou subjetivas, materiais ou culturais. Portanto, é na codeterminação situada entre realidade socioeconômica e estruturas informadoras que se concebe o indivíduo, ou seja, livre de todas as determinações aprioristicamente construídas por meio do racionalismo puramente abstrato e, em última análise, pelo próprio marxismo economicista/vulgar.

Após essas ponderações, a análise enfoca os pressupostos do individualismo metodológico e sua implicação na conexão entre Sociedade e Estado, mais especificamente na construção do interesse público.

Ora, se é verdade que o desenvolvimento ontológico de um determinado campo de estudo está inter-relacionado com as questões imediatas e latentes de um contexto, a Teoria da Escolha Pública configura-se não apenas como uma das formas acabadas do individualismo metodológico, ou seja, como forma racionalmente desenvolvida, mas também como resposta ideológica às crises estruturais do próprio metabolismo social. Portanto, ao se ter em conta o vínculo dado entre Sociedade e Estado, assim como a dimensão histórico-concreta, opina-se que tal abordagem - da Escolha Pública - é, sem dúvida, um dos grandes redutos das práticas neoliberais do limiar do século XXI.

Embora a "abordagem" da Escolha Pública empregue os "instrumentos utilizados pelo economista" para a análise social e política, mais especificamente "a teoria do comportamento da escolha individual" (BUCHANAN, 1970, p. 38), sua aproximação com a perspectiva sociológica da ação social é irrefutável, uma vez que compartilham o mesmo

2. Diferentemente da terminologia "gestão social", ou administração societal, adota-se o termo gestão societal, a fim de demarcar um paradigma de administração de organizações, não só alicerçado em engajamentos democráticos e suas diversas formas subjacentes de participação e mobilização, mas, sobretudo, voltado à gestão emancipadora e seu alcance para a crucial convergência política para a autogestão global da sociedade, conforme destacado em outro estudo nosso: Benini, Benini e Nemirovsky (2013) .

3. Sobre o estruturalismo dialético, no âmbito da Teoria das Organizações, ver Motta (1970). Para uma visão mais ampla sobre o estruturalismo, consultar Viet (1967). 
raciocínio lógico. Assim, para essa abordagem, é por meio do “[...] indivíduo humano como a entidade filosófica básica que deveríamos conceber o Estado como se fosse fundamentalmente derivado do consentimento individual" (BUCHANAN, 1970, p. 38).

É justamente nessa afirmação, do indivíduo como núcleo central, para o qual o comportamento racional, ou ação racional, ocorre sempre orientado no cálculo entre o meio e fim, que as abordagens econômica, política e sociológica, aqui descritas, convergem. Do lado da economia, esse argumento nuclear foi utilizado por Mises, que poderia ser reputado, juntamente com Menger (1983), como o reduto filosófico dessas proposições. De acordo com Mises (2010, p. 35), a "ação humana é o comportamento propositado", o que corresponde a dizer que a

[...] ação é a vontade posta em funcionamento, transformada em força motriz; é procurar alcançar fins e objetivos; é a significativa resposta do ego aos estímulos e às condições de seu meio ambiente; é o ajustamento consciente ao estudo do universo que lhe determina a vida.

Mas a particularidade das abordagens expostas é muito mais rica e sua desconsideração pode levar a análises e comparações rasteiras sobre questões profundas. Ainda que, para o sociólogo Max Weber (1999; 2012), aqui em discussão, a vinculação entre indivíduo e sociedade seja a mesma que da abordagem econômica (MISES, 1946; 2010; HAYEK, 1990; BUCHANAN; TULLOCK, 1962; BUCHANAN; 1970), o seu posicionamento sobre a ação racional baseada em valores pode levar a caminhos irreconciliáveis com o pressuposto da racionalidade comportamental do tipo egoísta/instrumental. Este é justamente o caso do interesse coletivo, como se elucida a seguir.

Ora, uma coisa que pode ser vista como irrefutável sobre a perspectiva individualística da economia é que a ação humana situada, logo específica/singular sob o ponto de vista temporal e espacial, seja a síntese do utilitarismo/egoísmo humano - característica marcante do homem no contexto do capitalismo. Outra coisa muito diferente é elevar tal proposição a um juízo sintético a priori e atribuir ao ser genérico do homem a naturalização do utilitarismo/egoísmo. Esse procedimento, efetuado com maestria por Mises (1946; 2010), por meio do seu axioma material autoevidente, além de criar uma circularidade lógica a-histórica, blinda a análise de todas as alteridades do comportamento humano.

Evidencia-se a consequência dessa lógica formal em uma de suas expressões de grande alcance, justamente a que recebeu o prêmio Nobel nos anos de decolagem da ideologia neoliberal:

[...] a mais conhecida dessas restrições, de novo retirada da economia, é a hipótese de que os indivíduos agem na política da mesma forma que presumivelmente agem na profética teoria dos mercados, de modo a maximizar sua utilidade esperada, e que seu comportamento ao fazê-lo seja mensurável em

4. É relevante ter em mente que, mesmo sendo um entusiasta da forma de legitimação racional-legal, o próprio Weber teceu importantes reflexões sobre o seu desenvolvimento, ainda que no plano lógico: "Neste último estágio de desenvolvimento cultural, seus integrantes poderão de fato, ser chamados de 'especialistas sem espírito, sensualistas sem coração, nulidades que imaginam ter atingindo um nível de civilização nunca antes alcançado'" (WEBER, 2004, p. 135). 
termos de alguma grandeza identificável objetivamente, como renda e riqueza (BUCHANAN, 1970, p. 40).

Eis aqui o construto de legitimação das práticas neoliberais. Ora, se a racionalidade do homem é sempre a maximização do seu ganho, ao se considerar a burocracia e a classe dos políticos com o mesmo raciocínio, a única forma de salvar a sociedade do parasitismo é a minimização dessas funções, o que significa, em termos práticos e concretos, a diminuição do próprio tamanho do Estado e de sua área de atuação.

É justamente da derivação lógica desse "homem racional", cujo comportamento é sempre orientado pelo seu ganho pessoal, que o interesse público, na qualidade de entidade exterior ao indivíduo, só pode ser concebido como uma realização moral que, para essa corrente teórico-metodológica, é apreendida como uma instituição artificial e estranha ao próprio homem. Assim, para Buchanan (1970, p. 41-45):

[...] não existe uma função do bem-estar social, nem um interesse público como tal, numa sociedade de indivíduos que escolhem livremente, e parece não haver razão para inventar tal concepção por conveniência analítica. [...] 0 modelo fundamenta-se numa desaprovação explícita de qualquer imputação pessoal de valores ético-morais ao sistema, [...], e mais importante, a análise deve partir de algum ponto, e o conjunto de regras e instituições existentes é o único lugar de onde é possível partir.

Outra questão que não pode passar sem a devida reflexão, de acordo com o modelo especificado, é o seu ponto de partida. Conforme exposto no decorrer deste texto, uma das características que culminam dessa abordagem é a negação dos acúmulos históricos na análise, elegendo o presente sempre como o ponto de partida. Tanto os acúmulos materiais-econômicos quanto a própria institucionalização historicamente constituída da convivência humana são colocados em segundo plano. É o fragmento frente a qualquer tentativa de visão de totalidade. Em síntese, é a expressão teórico-filosófica da própria crise da modernidade. Não é por acaso que os intelectuais apologistas da abordagem entendem a atual sociedade como pós-moderna, como bem aponta Harvey (2008).

Em vista da ideia de que a ação racional não é apenas instrumental, mas também pode se orientar por meio de valores (WEBER, 2012), na sequência explora-se a construção moral como forma de acúmulo histórico e, como derivação desse posicionamento, a própria legitimidade como estrutura ideológica significante da ação racional. Com isso, pondera-se que processos sociais de legitimidade podem servir a propósitos distintos ou até opostos.

\section{FORMAS HISTÓRICAS DE ADMINISTRAÇÃO: LEGITIMIDADE OU LEGITIMAÇÃO?}

Compreender uma construção moral como acúmulo histórico implica ampliar a sua análise com novos elementos, sendo, portanto, fundamental não se limitar a uma racionalização abstrata da realidade. De fato, talvez uma das principais críticas feitas pelo chamado 
socialismo "científico" à ideologia alemã e ao associativismo inglês ${ }^{5}$ - este conceituado primeiro de socialismo utópico - tenha sido justamente o apelo à moralização na produção das condições materiais da existência humana, ou seja, da própria economia política.

Em que pese essa enunciação sobre a constituição da moralidade social, quanto aos acúmulos históricos, tal construção embute per se uma produção material e sua aceitação social, ou seja, sua estrutura de dominação ou autoridade de significação. Isso ocorre devido à própria instabilidade de dinâmicas sociais que se formam sobre o solo inerentemente conflituoso e desagregador do antagonismo de classes.

Se a necessidade de coesão advém, sob o ponto de vista lógico, de um conjunto de partes ou elementos interdependentes, porém dispersos, a necessidade de coesão societária dos seres humanos constitui-se, sob o ponto de vista histórico, como condição de funcionalidade minimamente benéfica, ou que traz algum tipo de vantagem.

Por conseguinte, uma forma dominante de coesão e/ou organização social sempre será crucial em qualquer tipo de sociedade ou em fluxos de sociabilidade. Portanto, dominação, a rigor, não trataria per se e de imediato de uma coerção social - não obstante os processos decorrentes.

Tendo em vista tais desenvolvimentos lógicos, no caso das sociedades complexas, essas vantagens, em linhas gerais e em sentido amplo, referem-se tanto à segurança - individual e coletiva - de produção e reprodução do metabolismo social, quanto às descontinuidades estruturais necessárias para a continuidade do metabolismo.

Trata-se, simultaneamente, de um problema administrativo e de organização social, cuja intencionalidade sistêmica seria garantir os meios de coesão societária que possibilite algum tipo de vantagem que justifique uma dada sociabilidade. Tem-se, então, uma questão de ordem ideológica ou, segundo o argumento aqui desenvolvido de legitimidade, de construção moral no sentido de adesão consciente ou, de forma distinta, no propósito de assimilação passiva.

Se, por um lado, como assimilação passiva, vê-se um processo de legitimação - ato de regular algo que está em desconformidade -, uma vez que é uma construção unilateral, determinando uma forma de dominação alienadora, por outro, como adesão consciente, seria certamente um processo social legítimo - logo de qualidade per se, de caráter -, uma vez que resultaria de uma construção efetivamente coletiva e colaborativa, buscando o entendimento e/ou os meios práticos de coesão intersubjetiva.

Vale aqui abrir um breve excurso para ressaltar a relevância da diferenciação entre estrutura e sistema - este caracterizado essencialmente pela intencionalidade, conjunto e coerência - efetivada por Saviani (2012) que, sob a perspectiva da transformação social, tece uma sólida crítica à visão funcionalista dos sistemas sociais - como abstrações autossustentáveis de reprodução do metabolismo hierárquico vigente:

5. Para uma crítica contemporânea completa sobre a ideologia alemã, expressa nas proposições de "astúcia da Razão" de Hegel e "política moral" de Kant, recorrer à obra "O poder da ideologia", de István Mészáros (2004). Sobre o socialismo utópico e a proposta de cooperativismo operário, consultar "Burocracia e autogestão: a proposta de Proudhon" de Fernando Prestes Motta (1981). 


\begin{abstract}
A estrutura implica, portanto, a própria textura da realidade; indica a forma como as coisas entrelaçam entre si, independente do homem e, às vezes, envolvendo o homem (como no caso das estruturas sociais, políticas, econômicas, educacionais etc.). O sistema implica uma ordem que o homem impõe à realidade. Entende-se, porém: não se trata de criar a realidade. 0 homem sofre a ação das estruturas, mas, na medida em que toma consciência dessa ação, ele é capaz de manipular a sua força, agindo sobre a estrutura de modo a Ihe atribuir um sentido. [...]. Poder-se-á parafrasear [...]: o que foi feito do homem são as estruturas; o que ele faz (daquilo que fizeram dele) é o sistema (SAVIANI, 2012, p. 74-75).
\end{abstract}

Transpondo a tensão entre legitimação e legitimidade à singularidade do campo da administração, e considerando o exame crítico das chamadas escolas de administração (MOTTA, 2003; PAULA, 2008; FARIA, 2011; TRAGTENBERG, 2012), infere-se que a sua constituição, sob o ponto de vista histórico, foi determinada por necessidades tipicamente de legitimação, como meio de garantir a coesão societária.

Com isso, tem-se a sistematização - a rigor refletida e ideológica - de paradigmas de administração que não surgem tão somente como fruto da pesquisa e da elaboração de meios científicos de melhoria ou eficiência produtiva, mas, sobretudo, como resultado do próprio conflito social e ideológico.

Não por acaso observa-se que a primeira "escola de administração" é denominada de "administração científica". O apelo ao status de campo científico confere também um poder moral sobre as suas teses ou recomendações - o que a constituiu essencialmente como abordagem prescritiva-normativa (MOTTA, 2003).

Não é por casualidade que o poder moral adquire, como elemento prático de coesão societária, uma estrutura significante de dominação. Nessa estrutura, legitimação e racionalização - do antagonismo social - resultam em uma forma de coesão autoritária, viabilizada por formas hierárquicas de organização, ou melhor, pela divisão social hierárquica do trabalho, na qual o comando (dominação) do processo decisório é vertical, centralizado e advindo de um topo de poder/concepção para uma base de assimilação/execução. Tem-se aqui a formação histórica das organizações burocráticas, tanto no escopo imediato das empresas ou demais organizações da sociedade civil, como dos Estados nacionais.

Todo sistema social administrado segundo critérios racionais e hierárquicos é uma organização burocrática. Haverá organizações burocráticas mais flexíveis ou mais rígidas, mais formalizadas ou menos, mais ou menos autoritárias. Mas todas serão organizações burocráticas desde que o sentido básico do processo decisório seja de cima para baixo (MOTTA; BRESSER-PEREIRA, 1980, p. 13).

Apesar de inúmeras variações singulares, a depender de uma complexa teia de variáveis, a organização societária burocrática trilhou o caminho da legitimação como mecanismo ideológico e prática de coesão/dominação social. Em síntese magistral de Motta e Bresser-Pereira (1980, p. 13): 


\begin{abstract}
Temos pelo menos a organização burocrática patrimonial, pré-capitalista; a organização burocrática clássica, racional-legal, disciplinadora; a organização burocrática tecnocrática, orientada para a produção [...] Todas, entretanto, são antes de mais nada organizações burocráticas porque administradas segundo critérios de eficiência e forma hierárquica, estruturando-se o poder sempre de cima para baixo.
\end{abstract}

Reconhecendo o poder moral também como poder material, vê-se um processo de sofisticação das formas de dominação burocráticas, vindo desde paradigmas rudimentares como o patrimonialismo, culminando em formas mais recentes de dominação burocrática, como o desenvolvimento do gerencialismo (PAULA, 2005), mas todos eles formando verdadeiros grilhões de uma gestão pública efetivamente societária (BENINI; BENINI; NOVAES, 2012), como exibe a Tabela 1.

Tabela 1 - Paradigmas de administração, dominação e princípios

\begin{tabular}{ccc}
\hline $\begin{array}{c}\text { Paradigmas de } \\
\text { Administração }\end{array}$ & $\begin{array}{c}\text { Dominação/autoridade/ } \\
\text { Aceitação/vínculo }\end{array}$ & Princípios/Pilares edificantes \\
\hline Patrimonial & Tradicional. Carismático & Fidelidade pessoal. Fisiologismo. Clientelismo \\
\hline Burocrático & Racional/legal & $\begin{array}{c}\text { Universalidade de procedimentos. Racionalidade } \\
\text { Instrumental. Eficiência. Hierarquia. Formalidade. } \\
\text { Centralização. }\end{array}$ \\
\hline Gerencial & Resultado/sucesso & $\begin{array}{c}\text { Flexibilização. Eficácia. Descentralização. } \\
\text { Accountability. }\end{array}$ \\
\hline Societal & Democracia Real & $\begin{array}{c}\text { Autogestão. Igualdade Substantiva. Racionalidade } \\
\text { Substantiva. Emancipação. }\end{array}$ \\
\hline
\end{tabular}

Fonte: Elaboração dos autores (2016).

Tendo em vista essa relação direta entre paradigmas de administração e formas de coesão/dominação societária, a descontinuidade dos mecanismos de dominação e seus princípios entre os paradigmas de administração patrimonialista, burocrático e gerencial é articulada pela continuidade de uma estrutura hierárquica e antagônica de dominação/ coesão. Porém, não se trata de uma continuidade linear. 0 próprio desenvolvimento do gerencialismo revela a sua instabilidade e as suas contradições, uma vez que é resultado tanto do esgotamento do fordismo/keynesianismo - forma de regulação caracterizada pela produção/consumo em massa e atuação do Estado na promoção do crescimento econômico e de políticas sociais - como também pelo esgotamento do discurso ideológico que sustentava politicamente uma gestão burocrática típica (ANTUNES; ALVES, 2004).

Com a crise na capacidade dos Estados nacionais de regular as fraturas do intercâmbio capitalista mercantil, isto é, promover a imprescindível coesão/dominação societária, tal forma de dominação passa a utilizar novos princípios ou ferramentas de gestão. Assim, se 0 universalismo de procedimentos e a racionalização massiva ou padronizada foram adequados ao fordismo, o apelo à flexibilidade de procedimentos e a eficácia no resultado 
hierarquicamente imposto - da rentabilidade financeira - passam a ser uma necessidade material de organização social, catalisada e blindada pelo apelo moral das supostas "novas realidades" da chamada sociedade pós-capitalista e pós-industrial (DRUCKER, 1997).

Ressalta-se, ainda, que é justamente nesse contexto que ganham força o movimento "reinventando o governo" (OSBORNE; GAEBLER, 1994) e a ideologia neoliberal, assim como a sua correspondente forma estética, expressa nas obras de arte, literatura e arquitetura, de cariz pós-modernista, como argumenta Harvey (2008), ao retratar as mudanças do fordismo para a contemporânea acumulação flexível.

Outrossim, tal construção moral, se por um lado inflaciona as supostas virtudes da superação, da adaptação, da qualificação, sob a ótica do indivíduo frente ao mercado de trabalho e de consumo, por outro, silencia sobre a realidade da precarização do trabalho, advinda de formas de produção/organização poupadoras de força de trabalho humano e centrada na determinação hierárquica da acumulação de capital para a classe dominante.

Tabela 2 - Paradigmas de administração, pacto de regulação e estética filosófica

\begin{tabular}{ccc}
\hline Paradigmas de Administração & Regulação & Estética filosófica \\
\hline Patrimonial & Tradicional & Pré-moderna \\
\hline Burocrático & Fordismo/Keynesianismo & Moderna \\
\hline Gerencial & Toyotismo/Neoliberalismo & Pós-moderna \\
\hline Societal & Autogestão & $?$ \\
\hline
\end{tabular}

Fonte: Elaboração dos autores (2016).

O gerencialismo, portanto, vem ressignificando a burocracia, gerando novas - e velhas - estruturas significantes de coesão societária, como a tecnocracia, a eficiência organizacional, uma benevolente competitividade, a pedagogia das competências e a empregabilidade, todas elas como artifícios para o sucesso nos negócios e nos resultados - em geral financeiros ou de riqueza meramente econômica.

Entretanto, tendo em vista o processo histórico que direcionou a coesão societária para um modo instrumental e alienador de dominação, portanto, de assimilação passiva promovida e reproduzida por um conjunto de instrumentos administrativos - ou paradigmas de administração - intentando a legitimação, tais formações burocráticas de organização social abrigaram em si a sua própria alteridade, a saber, o paradigma de gestão societal ou de organização autogestionária, apesar da dominação ostensiva e sufocante - em termos de pensar/propor alternativas - das organizações burocráticas sobre a atual sociabilidade humana. Assim, torna-se mister não desconsiderar a existência de alternativas para a organização burocrática, tanto no aspecto lógico quanto, principalmente, histórico-concreto. Como explanam Motta e Bresser-Pereira (1980, p. 13), "[...] ela existe exclusivamente na forma de organização democrática ou autogestionária em que a racionalidade administrativa se expressa no sentido inverso, de baixo para cima".

Por sua vez, no que tange aos aspectos lógicos e históricos, tal paradigma de organização democrática tem se consubstanciado por meio de um duplo caminho, nem sempre convergente - causa essencial de sua debilidade e fragmentação: primeiro, como necessida- 
de moral de superação da dominação de caráter burocrático e hierárquico; segundo, como necessidade material de um processo legítimo de coesão societária de forma horizontal, igualitário e propositivo, ou melhor, estruturado justamente pela adesão consciente, e assim intencional, dos seres humanos como seres sociais ou que intentam uma sociabilidade efetivamente coletiva e colaborativa/ou não alienadora. Tal perspectiva revela-se como verdadeiro potencial histórico em aberto, ao se compararem os paradigmas de administração no tocante à sua forma de controle e instituições correspondentes, como mostra a Tabela 3.

Tabela 3 - Paradigmas de Administração, Controle e Instituições

\begin{tabular}{ccc}
\hline $\begin{array}{c}\text { Paradigmas de } \\
\text { Administração }\end{array}$ & Controle & Instituições \\
\hline Patrimonial & No sujeito & $\begin{array}{c}\text { Empreendimentos de concessão. Estado } \\
\text { patrimonial. Modo de produção asiático }\end{array}$ \\
\hline Burocrático & No processo & $\begin{array}{c}\text { Empresa moderna verticalizada. Estado forte. } \\
\text { Instituições públicas concretas. }\end{array}$ \\
\hline Gerencial & No resultado & $\begin{array}{c}\text { Empresa flexível. Estado mínimo. Instituições } \\
\text { como regras. }\end{array}$ \\
\hline Societal & $\begin{array}{c}\text { No metabolismo social - conjun- } \\
\text { to das atividades vitais para a } \\
\text { reprodução social }\end{array}$ & $\begin{array}{c}\text { Produção associada. Experiências de participa- } \\
\text { ção popular, etc. }\end{array}$ \\
\hline
\end{tabular}

Fonte: Elaboração dos autores (2016).

Articulando as Tabelas 1, 2 e 3 transparece que o paradigma de gestão societal é elemento intrínseco à democracia. Resulta de uma sociedade plenamente democrática, capaz de autodeterminar o conjunto das atividades vitais para uma benevolente reprodução social dos seus integrantes.

Sem embargo, uma dada sociabilidade somente poderia ser, a rigor, democrática, quando a própria dominação dos processos de coesão social também for substantivamente democrática ${ }^{6}$. Tal processo sugere justamente a negação do próprio eixo fundante do metabolismo do capital e sua estrutura autoritária-burocrática-hierárquica. Em outras palavras, a democracia consubstancia-se em formas de organização e administração societárias quando a coesão social é dominada/estruturada pelo interesse coletivo.

O próprio Weber já lançava indícios do que poderia ser apreendido como uma quarta forma de dominação. Dada a pouca disseminação dessa reflexão de Weber, torna-se mister conhecê-la ipsis litteris:

A dominação nos interessa aqui, em primeiro lugar, sob o aspecto de sua vinculação à 'administração'. Toda dominação manifesta-se e funciona como administração. Toda administração precisa, de alguma forma, da dominação, pois, para dirigi-la, é mister que certos poderes de mando se encontrem nas mãos de alguém. 0 poder de mando pode ter aparência muito modesta,

6. Para consultar uma seminal contribuição sobre o alargamento da democracia social na sociedade como condição sine qua non de ampliação da democracia política, ver Bobbio (2007). 


\begin{abstract}
sendo o dominador considerado o 'servidor' dos dominados e sentindo-se também como tal. Isso ocorre, em mais alto grau, na chamada administração diretamente democrática. Chama-se 'democrática' por duas razões que não coincidem necessariamente, a saber: 1) porque se baseia no pressuposto da qualificação igual, em princípio, de todos para a direção dos assuntos comuns, e 2) porque minimiza a extensão do poder de mando. As funções administrativas são simplesmente assumidas num sistema de turno ou conferidas mediante sorteio ou eleição direta, para curtos períodos de exercício, sendo reservadas aos membros da associação todas as decisões materiais, ou pelo menos as importantes, e deixadas com os funcionários somente a preparação e a execução das decisões e a chamada 'administração dos assuntos', de acordo com as disposições da assembleia dos membros. Seguem este esquema a administração de muitas associações privadas bem como a de comunidades políticas [...] e de muitas outras formações semelhantes" (WEBER, 1999, p. 193).
\end{abstract}

Como processos já em formação, o paradigma da administração societal já ensaia a sua práxis em diferentes espaços de experimentação utópica, aponta Weber, não obstante as limitações impostas pelo contexto tecnológico do seu tempo, como se verifica nesta outra passagem:

\begin{abstract}
Esse tipo de administração é praticado, em regra, em associações que estão limitadas 1) localmente ou 2) quanto ao número dos participantes, além de estarem pouco diferenciadas 3 ) no que se refere à situação social dos membros, e ele pressupõe 4) tarefas relativamente simples e estáveis e 5) apesar disso, um grau não totalmente insignificante de desenvolvimento da competência de avaliar, objetivamente, meios e fins (WEBER, 1999, p. 193).
\end{abstract}

Embora as declarações de Weber sejam provocantes, principalmente no que diz respeito aos limites situacionais levantados, a dominação do princípio da democracia ainda é vista - em Weber - como metodologia administrativa de forma restrita, e não como necessário elemento de controle das atividades vitais de uma dada e complexa sociabilidade. Neste ponto, frisa-se mais uma vez, é fundamental não perder de vista que as condições materiais e tecnológicas vivenciadas por Weber eram muito diferentes das atuais tecnologias de informação e comunicação, indispensáveis para o avanço da democracia em todas as dimensões e organizações, conforme muito bem argumentam pensadores contemporâneos como Bobbio (2007) e Dallari (2007) e, não mesmo relevante, por pensadores que compreendem a emancipação a partir dos processos de comunicação e da intersubjetividade, como um dos maiores expoentes desse campo epistemológico, Jügen Habermas (2003), há tempos vem defendendo.

\title{
O PRINCÍPIO DA DEMOCRACIA: LEGITIMIDADE E ADMINISTRAÇÃO PARA A EMANCIPAÇÃO
}

Apesar de a maioria dos Estados nacionais gozar de um regime político estatal conceituado formalmente como democrático, a sua forma dominante de organização social permanece burocrática em termos administrativos e patrimonialista em termos políticos. Isso porque a democracia teve o seu escopo e abrangência reduzidos historicamente 
(WOOD, 2011). O campo da produção foi simplesmente retirado da esfera pública e isolado/protegido como propriedade privativa dos indivíduos. Com isso, a segmentação do corpo societário ocorre em duas dimensões: a do público estatal e a do privado, que, por sua vez, fragmentam em distintas organizações as atividades vitais da reprodução social ${ }^{7}$.

Mészáros (2002; 2004; 2015) tem anunciado que esse processo de múltiplas fragmentações tem produzido fraturas entre as esferas da produção, controle e circulação/ socialização, ocasionando um distúrbio estrutural do sociometabolismo vigente, transparecendo características como irreformabilidade, incontrolabilidade e destrutividade. 0 próprio Mészáros (2002, p. 105) descreve:

Primeiro, a produção e o controle estão radicalmente isolados entre si e diametralmente opostos. Segundo, no mesmo espírito e surgindo das mesmas determinações, a produção e o consumo adquirem uma independência e uma existência separada extremamente problemáticas, de modo que, no final, o "excesso de consumo" mais absurdamente manipulado e desperdiçador, concentrado em poucos locais, encontre seu corolário macabro na mais desumana negação das necessidades elementares de incontáveis milhões de pessoas. E, terceiro, os novos microcosmos do sistema do capital combinam-se em alguma espécie de conjunto administrável, de maneira que o capital social total seja capaz de penetrar - porque tem de penetrar - no domínio da circulação global (ou, para ser mais preciso, de modo de que seja capaz de criar circulação como empreendimento global de suas próprias unidades internamente fragmentadas), na tentativa de superar a contradição entre produção e circulação. Dessa forma, a necessidade de dominação e subordinação prevalece, não apenas no interior de microcosmos particulares - por meio da atuação de cada uma das personificações do capital - mas também fora de seus limites, transcendendo não somente todas as barreiras regionais, mas também todas as fronteiras nacionais.

É a partir dessas contradições, entre produção e controle, produção e consumo, e produção e distribuição - todas relacionadas com a subsunção do valor de uso ao valor de troca - que o Estado moderno assume um papel vital para o funcionamento do sistema, que é justamente controlar, de modo abrangente, as forças centrífugas que emanam de organizações produtivas isoladas, portanto, "um sistema reprodutivo social antagonicamente estruturado" (MÉSZÁROS, 2002, p. 107).

Essa incontrolabilidade intransponível do sistema metabólico hegemônico tem, como fundamento e sustentáculo, uma forma de organização social estruturada pelo e para o capital, isto é, por mediações sociais que segregam os seres humanos em classes antagônicas, cujo propósito impõe, mutatis mutandis, a exploração de uma sobre a outra, de forma hierarquizada e alienadora, determinando a coisificação inclusive da própria natureza externa dos seres humanos ou os sistemas ecológicos que, dentre outras funções vitais, permitem justamente a nossa existência material - isto posto independentemente da forma de propriedade aceita ou imposta socialmente, como foi observado no chamado socialismo

7. Atividades vitais são todas aquelas essenciais para a sobrevivência imediata das pessoas e a convivência mediada socialmente, mas que estão intrinsicamente vinculadas. Logo, tanto a questão da produção de alimento, moradia, infraestrutura, entre outros está relacionada com a promoção de serviços em geral, como os de educação, saúde e segurança. 
real, uma vez que a alteração da estrutura patrimonial não correspondeu a uma alteração da estrutura hierárquica de comando e controle, portanto, do centro irradiador dos processos de alienação e estruturação de classes antagônicas.

Há um limite histórico da dominação burocrática hierárquica ou da assimilação passiva dessa forma de coesão social: os limites estruturais do sistema sociometabólico do capital. Há nisso um imperativo de superação, em todos os sentidos, da circularidade alienadora desse metabolismo social, responsável por aprofundar um conjunto crescente de problemáticas societários, tais como desemprego econômico, exclusão social, degradação ambiental, desperdícios produtivos, conflitos políticos, alienação individual.

Esse imperativo de superação das formas de administração sem legítima concreção societária - com destaque ao Estado, de caráter essencialmente burocrático e, por isso, divorciado de uma legítima esfera pública - implica, de maneira consciente e intencional, o reconhecimento dos problemas e das ações práticas primordiais, portanto, o próprio processo de transcendência positiva dos múltiplos processos de alienação, promovido pela autotranscendência humana da sua condição societal subalterna. Mészáros (2002, p. 595) comenta:

[...] o "fenecimento" do Estado implica não apenas o "fenecimento" do capital (como o controlador objetivado e reificado da ordem social-reprodutiva), mas também a auto-transcendência do trabalho da condição de subordinado aos imperativos materiais do capital imposta pelo sistema prevalecente da divisão estrutural/hierárquica de trabalho e poder estatal. Isto é possível apenas se todas as funções de controle do sociometabolismo - que sob todas as formas de dominação do capital devem estar investidas na estrutura de comando material e política de um poder de tomada de decisão alienado - forem progressivamente apropriadas e positivamente exercidas pelos produtores associados. Nesse sentido, o afastamento estrutural objetivo das personificações do capital (em vez do político-jurídico insustentável por si mesmo) por meio de um sistema de autoadministração genuíno é a chave para a reconstrução bem-sucedida das estruturas herdadas.

Explicita-se aqui uma legítima necessidade material como estrutura significante da democracia, portanto, de sua práxis substantiva como formas históricas ou em constituição crítica de administração societal. Essa práxis advém da necessária confluência, sob o ponto de vista material e moral, de coesão societária para um efetivo controle sociometabólico, isto é, de autodeterminação societal ou da dominação do princípio substantivo da democracia e não da hierarquia social de classe. Nos dizeres ainda de Mészáros, há o seguinte desafio para a concretização e a multiplicação dessas estruturas de caráter democratizante:

[...] isso significa que a remoção não se dá apenas na forma da inevitável transcendência crítica, mas, muito mais importante, pela apropriação positiva e pela melhoria contínua das funções vitais de intercâmbio metabólico com a natureza e entre os membros da sociedade pelos próprios indivíduos que se autodeterminam. (MÉSZÁROS, 2002, p. 912). 
O desenvolvimento da práxis substantiva imperiosa para a estruturação da administração societal deve, por sua vez, ser caracterizado pela promoção de uma verdadeira sociabilidade, que se cristalize, em todas as suas instâncias de intercâmbio, no controle e na propriedade real dos meios de decisão e produção da vida social, sendo, portanto, a forma histórica de convergência entre o indivíduo e a sua atividade.

Os paradigmas de administração patrimonial, burocrático e gerencial submetem-se integralmente a um mecanismo de regulação metabólica, cujo epicentro se manifesta na relativização radical do indivíduo social, operada, sobretudo, por relações de dominação material e moral exercidas sobre ele. Tendo como referência a própria história concreta, tal manifestação ocorreu tanto nas formas tradicionais/liberais de dominação, no chamado pacto fordista/keynesiano, quanto na contemporânea desregulamentação de orientação neoliberal - cuja base material se encontra na chamada reestruturação produtiva de cariz flexível -, todas elas se amparando na mistificação do indivíduo, das contradições socioeconômicas e da racionalidade da ação humana (ANTUNES; ALVES, 2004).

Em meio a essas formas fetichizantes de organização do metabolismo social, devem ser incluídas as tentativas de democratização forçada praticadas no âmbito da constituição de órgãos colegiados consultivos e deliberativos para a coprodução de políticas públicas estatais ${ }^{8}$. Em que pesem as possibilidades estruturais de caráter emancipatório que tais processos podem desencadear - ou contradições positivas -, é importante não perder de vista que os limites históricos e materiais desses organismos democráticos estão aqui explícitos na estabilização pretendida da fratura estrutural entre Estado político - sociedade política - e sociedade civil, na qual a última se vê completamente mistificada, de acordo com Montaño (2003), sob o manto de sociedade civil organizada presente na fábula da terceira via preconizada por Fukuyama (2001) e Giddens (1998).

Em sua crítica da filosofia do direito de Hegel, Marx (2010) já afirmava, adentrando à discussão polarizada entre Monarquia e República, que tal debate ainda se encontrava inserido no âmbito da esfera política meramente abstrata, constitucional, o mesmo ocorrendo com os mecanismos participativos projetados para a democratização pretensa da produção de políticas públicas estatais, que desconsidera o campo da produção material em sentido amplo. Portanto, para superar esse fetiche da organização social, é inadiável o compromisso da administração societal com a ruptura estrutural da burocracia e suas formas mistificadas, reestruturando, desde as instâncias de decisão mais simples até as mais complexas, os mecanismos de administração imprescindíveis que tornem imanentes as condições de participação efetiva dos indivíduos, além das formas abstratas de participacionismo ${ }^{9}$, com o

8. No que diz respeito à coprodução de políticas públicas, dois pontos precisam ser enfatizados: que no plano formal-discursivo, tal mecanismo de gestão de políticas públicas - formulação e implementação - coloca-se como resultado de um novo movimento, denominado Novo Serviço Público (New Public Service), que se diferencia tanto da Administração Pública "Tradicional", burocrática, quanto da Nova Administração (New Public Management) - na qual estariam inseridas as concepções gerencialistas - e que tanto a sua ontogênese ideológica quando a sua reprodução acadêmica a colocam como a forma mais democrática de produção de bens e serviços públicos (DENHARDT; DENHARDT, 2000; 2003).

9. Dialeticamente, os processos de participação, ou ainda, de democratização, ao mesmo tempo em que favorecem novas estruturas sociais, cognitivas e culturais, quando não são aprofundados e efetivamente ampliados, tornam-se verdadeiros instrumentos de manipulação e reprodução do status quo, como muito bem argumentou Tragtenberg (2011), ao comparar e ironizar o participacionismo com Alice no País das Maravilhas. 
inevitável avanço progressivo da sociedade civil em direção à sociedade política, e não para a perpetuação do antagonismo estrutural entre esta e aquela.

A administração societal manifesta o seu caráter emancipador e autonomista, revestindo-se das experiências históricas de autodeterminação dos indivíduos sociais, tais como o cooperativismo revolucionário europeu, a comuna de Paris, os sovietes pré-revolução russa, a Revolução dos Cravos de 1974 em Portugal, as fábricas recuperadas na América Latina etc (NOVAES, 2007). Isso implica, ainda, reconhecer que a democracia, como práxis emancipatória, exigida para a consumação da administração societal, deva superar a aparente neutralidade das relações sociais e a atomização relativa dos indivíduos, orquestrada pela burocracia, submetendo tudo e todos aos imperativos do interesse coletivo universal dos sujeitos sociais, e, somente assim, interesse efetivamente público.

Essa reflexão impõe, ainda, que a democracia pretendida supere estruturalmente as vicissitudes hierarquizantes típicas do modelo socialdemocrata de representação, o que revela a estreita e permanente aproximação necessária entre a democracia e uma ética de fato libertária, tal como analisou Lukács em seu manifesto de 1947:

\begin{abstract}
A verdadeira democracia - a nova democracia - produz em todos os lugares transições reais, dialéticas, entre a vida privada e a pública. A mudança decisiva na nova democracia é que agora se participa das interações da vida pública com a privada como sujeito ativo e não como objeto passivo [...] A nova fase eticamente emergente demonstra, acima de tudo, que a liberdade de um não é uma ameaça à liberdade do outro, mas sua precondição. $O$ indivíduo não pode ser livre senão numa sociedade livre. [...] A autoconsciência emergente da humanidade anuncia, como perspectiva, o fim da "pré-história humana". Com isto, a autocriação do homem adquire uma nova ênfase; agora vemos a emergência, como tendência, da unidade entre a autoconstituição humana do indivíduo e a autocriação da humanidade. A ética é um elo intermediário crucial neste processo como um todo (apud MÉSZÁROS, 2002, p. 371).
\end{abstract}

O argumento de Lukács demarca precisamente os imperativos sociomateriais que orientam a concepção adequada sobre a administração societal. A ética mostra-se como mecanismo regulador historicamente primordial, uma vez que representa, por um lado, o intercâmbio orgânico entre a sociabilidade humana e a reprodução material da humanidade e, por outro, a unidade entre as necessidades morais e materiais da organização social.

É exatamente essa unidade, traduzida pelo intercâmbio entre a ética libertária e a democracia como práxis emancipatória, que se ressalta como um dos pilares indispensáveis para a construção de uma democracia real e substantiva.

\title{
CONSIDERAÇÕES FINAIS: A DEMOCRACIA COMO DOMINAÇÃO DO INTERESSE PÚBLICO
}

Constituir uma sociabilidade caracterizada pela dominação do princípio da democracia significa estruturar, sistematicamente - com o claro sentido de intencionalidade -, uma realidade de autodeterminação dos indivíduos, fundada em relações sociais, culturais, políticas e econômicas, horizontais e interdependentes entre si. Portanto, mais do que uma 
gestão social, para que se possa avançar, é vital ter a perspectiva de uma autogestão societária como totalidade dialética.

Por sua vez, considerando justamente a codeterminação dialética entre a dinâmica das relações sociais e estruturas socioprodutivas resultantes, o paradigma da administração societal qualifica, por sua natureza e práxis, a própria democracia resultante como um processo de dominação do interesse coletivo - em primeira aproximação material - e público - como resultado agregador moral - na equação indivíduo e sociedade.

O interesse público surge, então, não apenas como necessidade material de coesão societária para o controle do metabolismo social, mas também como enriquecimento ideológico resultante dessa construção histórica. Ora, eis aqui o interesse público revigorado pela necessidade moral de emancipação social dos seres humanos. Demarca-se, assim, uma crítica às formas burocráticas de administração, pontuando a administração societal como paradigma valioso para se projetar um novo horizonte de práticas organizativas, voltado à democracia real dos indivíduos sociais e orientado por uma ética basilarmente libertária.

A administração societal evidencia-se como forma de administração cujo fundamento democrático visa a superar as contradições da alienação entre as esferas pública e privada, colocando em perspectiva a dissolução das contradições perpetradas pela dissociação entre os interesses privado, particular e coletivo. Dissolvem-se, também, as discussões que pretendem recair sobre uma infrutífera separação entre o que se deve entender sobre administração pública societal ou uma gestão social de caráter privado.

Igualmente, o paradigma da administração societal se encaminha além das discussões sobre a racionalidade administrativa expressada nos processos decisórios - de cima para baixo ou de baixo para cima, como pretendem Motta e Bresser-Pereira (1980) -, uma vez que o objetivo último da administração societal é exatamente dissolver as instâncias de dominação antidemocráticas e, por isso, romper completamente com as posições hierárquicas.

\section{REFERÊNCIAS}

ANTUNES, R.; ALVES, G. As mutações no mundo do trabalho na era da mundialização do capital. Educação \& Sociedade. v. 25. n. 87, p. 335-351, 2004.

BENINI, E. A.; BENINI, E. G.; NOVAES, H. T. Os grilhões da gestão pública: o processo decisório e as formas contemporâneas de dominação patrimonialista. Cadernos Gestão Social, v. 3, n. 1, p.85-100, 2012.

BENINI, E. A.; BENINI, E. G; NEMIROVSKY, G. G. Convergência política para a construção da autogestão global. Revista Org \& Demo, Marília, v. 14, n. 1, 2013.

BERNARDO, J. Marx crítico de Marx. Porto: Afrontamento, 1977.

BOBBIO, N. Estado, governo e sociedade: para uma teoria geral da política. São Paulo: Paz e Terra, 2007.

BUCHANAN, J. M. Uma teoria individualística do processo político. In: EASTON, D. Modalidades de análise política. Rio de Janeiro: Zarar Editores, 1970. 
BUCHANAN, J. M.; TULLOCK, G. The calculus of consent: logical foundations of constitutional democracy. Ann Arbor: Michigan University Press, 1962.

BURREL, G.; MORGAN, G. Sociological paradigms and organizational analysis: elements of the sociology of corporate life. London: Heinemann, 1979.

CALDAS, M.P. Paradigmas em Estudos Organizacionais: Uma Introdução à Série. Revista de Administração de Empresas, São Paulo, v. 45, n. 1, p. 53-57, 2005.

CLEGG, S. R.; HARD, C.; NORD, W. R. Handbook of organization studies. London: Sage, 1996.

DALLARI, D.A. Elementos de teoria geral do Estado. São Paulo: Saraiva, 2007.

DEETZ, S. Describing Difference in Approaches to Organization Science: Rethinking Burrell and Morgan and Their Legacy. Organization Science, Hanover, v. 7, n. 2, p. 191-207, 1996.

DENHARDT, R.B.; DENHARDT, J.V. The New Public Service: Serving Rather than steering. Public Administration Review, v. 60, n. 6, p. 549-59, 2000.

DENHARDT, R.B.; DENHARDT, J.V. The New Public Service: serving, not steering. New York: M. E. Sharpe, 2003.

DONALDSON, L. In Defence of Organization Theory. A Reply to the Critics. Cambridge: Cambridge University Press, 1985. 196 p.

DRUCKER, P. As novas realidades. São Paulo: Pioneira, 1997.

FARIA, J.H. Economia política do poder: uma crítica da teoria geral da administração. v. 2. Curitiba: Juruá Editora, 2011.

FUKUYAMA, F. Social capital, civil society and development. Third World Quarterly, v. 22, n. 1, p. 7-20, 2001.

GIDDENS, A. The third way: the renewal of social democracy. Cambridge: Polity Press, 1998.

GRAY, J. Falso amanhecer: os equívocos do capitalismo global. Rio de Janeiro: Record, 1999.

HABERMAS, J. Teoría de la acción comunicativa: racionalidad de la acción y racionalización social. Buenos Aires: Taurus, 2003.

HARVEY, D. Condição Pós-Moderna. São Paulo: Editora Loyola, 17a. edição, 2008.

HASSARD, J. Multiple Paradigms and Organizational Analysis: a case study. Organization Studies, London, v. 12, n. 2, p. 275-299, 1991.

. Sociology and Organization Theory. Positivism, Paradigms e Postmodernity. Cambridge: Cambridge University Press, 1993. 168 p.

HAYEK, F. O caminho da servidão. Rio de Janeiro: Instituto Liberal, 1990.

JACKSON, N.; CARTER, P. "Paradigms Wars": A Response to Hugh Willmott. Organization Studies, London, v. 14, n. 5, p. 727-730, 1993.

LUKÁCS, G. Para a ontologia do ser social. v. 1. São Paulo: Boitempo Editorial, 2012. 
LUKÁCS, G. Para a ontologia do ser social. v. 2. São Paulo: Boitempo Editorial, 2013.

KUHN, T. The structure of scientific revolutions. Chicago: University of Chicago Press, 1969.

MARX, K. Crítica da filosofia do direito de Hegel. São Paulo: Boitempo Editorial, 2010.

MENGER, C. Princípios de Economia Política. São Paulo: Abril Cultural, 1983.

MÉSZÁROS, I. Para além do capital. São Paulo: Boitempo Editorial, 2002.

. 0 poder da ideologia. São Paulo: Boitempo Editorial, 2004.

. A montanha que devemos conquistar: reflexões sobre o Estado. São Paulo: Boitempo Editorial, 2015.

MISES, L.V. Bureaucracy. New Haven: Yale University Press, 1946.

Brasil, 2010.

Ação Humana: um tratado de economia. São Paulo: Instituto Ludwig von Mises MOTTA, F.P. O estruturalismo na Teoria das Organizações. RAE - Revista de Administração de Empresas, São Paulo, v. 4, n. 10, p. 23-41, 1970.

Burocracia e autogestão: a proposta de Prouddhon. São Paulo: Brasiliense, 1981. 2003.

Teoria das organizações: evolução e crítica. São Paulo: Pioneira Thomson Learning,

MOTTA, F.P.; BRESSER-PEREIRA, L.C. Introdução à organização burocrática. São Paulo: Brasiliense, 1980.

MONTAÑO, C. Terceiro setor e questão social: crítica ao padrão emergente de intervenção social. São Paulo: Cortez, 2003.

NOVAES, H.T. O Fetiche da Tecnologia: a experiência das fábricas recuperadas. São Paulo: Expressão Popular/Fapesp, 2007.

OSBORNE, D.; GAEBLER, T. Reinventando o governo: como o espírito empreendedor está transformando o setor público. Brasília: MH Comunicação, 1994.

PARKER, M.; MCHUGH, G. Five Texts in Search of an Author: A Response to John Hassard's "Multiple Paradigms and Organizational Analysis". Organization Studies, London, v. 12, n. 3, p. 451-456, 1991.

PAULA, A.P.P. Por uma nova gestão pública. Rio de Janeiro: Editora da Fundação Getúlio Vargas, 2005.

. Teoria crítica das organizações. São Paulo: Thompson Learning, 2008.

Para além dos paradigmas nos Estudos Organizacionais: o Círculo das Matrizes

Epistêmicas. Cad. EBAPE.BR, Rio de Janeiro, v. 14, n. 1, p. 24-46, 2016.

PIKETTY, T. 0 capital no século XXI. Rio de Janeiro: Intrínseca, 2014.

SAVIANI, D. Educação Brasileira: Estrutura e Sistema. Campinas: Autores Associados, 2012. 
SILVEIRA, R.Z. Mãe!? O mundo vai acabar...? Reflexões sobre Desdobramentos e Implicações dos Paradigmas Sociológicos de Burrell e Morgan para os Estudos Organizacionais. Cad. EBAPE.BR, Rio de Janeiro, v. 11, n. 4, p. 652-670, 2013.

TRAGTENBERG, M. Administração, poder e ideologia. São Paulo: Editora Unesp, 2011. . A teoria geral da Administração é uma ideologia? In: TRAGTENBERG, M. Educação e burocracia. São Paulo: Editora Unesp, 2012.

VAISMAN, E. Ideologia e sua determinação ontológica. Verinotio. v. 6, n. 12, p.40-64, 2010.

VIET, J. Métodos estruturalistas nas ciências sociais. Rio de Janeiro: Tempo Brasileiro, 1967.

WEAVER, G.R.; GIOIA, D.A. Paradigms Lost: Incommensurability vs. Structurationist Inquiry. Organization Studies, London, v. 15, n. 4, p. 565-590, 1994.

WEBER, M. Economia e sociedade: fundamentos da sociologia compreensiva. Brasília: Editora Universidade de Brasília, 1999.

A ética protestante e o espírito do capitalismo. São Paulo: Martin Claret, 2004.

. Economia e sociedade: fundamentos da sociologia compreensiva. Brasília: Editora Universidade de Brasília, 2012

WOOD, E.M. Democracia contra Capitalismo: a renovação do materialismo histórico. São Paulo: Boitempo, 2011.

Data de Submissão: 18/05/2016.

Data de Aprovação: 19/05/2017. 